\title{
Comparative Study of Vehicular Ad-hoc Network Mobility Models and Simulators
}

\author{
Mitul K. Patel \\ Gujarat Technological University \\ Shree Swami Atmanand Saraswati Institute of Technology, \\ Surat
}

\begin{abstract}
Vehicular Networking is an emerging area of interest in the wireless networking community as well as in the transportation research community. The potential of vehicular networks to provide vital services, from real time traffic information to advance collision warning, makes this an important area of study. Vehicular Ad-hoc Networks (VANETs) id defined as self-organized network which have moving vehicles and also it is considered as a sub part of Mobile Ad-hoc Networks (MANETs). In order to test the feasibility and performance of VANET, it requires some specific networking methodology which can be checked and tested with the help of simulation. The characterization of vehicular mobility at microscopic and macroscopic level is considered as the major challenge in VANET. In this paper, there will be discussion about various mobility models available for VANET and also there will be a comparative study of network and traffic simulators available for VANETs.
\end{abstract}

\section{General Terms}

Vehicular Ad-hoc Network, Mobility Model, Mobile Ad-hoc Network

\section{Keywords}

VANET, MANET

\section{INTRODUCTION}

The main characteristic of VANET is that it is created by moving vehicles having very high speed and constrained by node movement patterns. Such particular features often make standard networking protocols inefficient or unusable in VANETs [2].

Road safety is a critical issue, considering parameters like magnitude and gravity and also it can cause negative impacts on the national economy, health of common man and the general welfare of the people. Today, RTIs (Road Traffic Injuries) are one of the leading causes of deaths, disabilities and hospitalizations, with severe socioeconomic costs, across the world. World Health Statistics 2008 cited in Global Status Report on Road Safety states that RTIs in 2004 were the $9^{\text {th }}$ leading cause of death and at current rates by 2030 are expected to be the $5^{\text {th }}$ leading cause of death, overtaking diabetes and HIV/AIDS [5]. One such survey is shown in figure -1 that shows the increase in accident severity from year 2001 to 2010.

In VANET, communications between nodes are direct, i.e. without relying on any dedicated infrastructure, contrary to earlier vehicular networks [4]. Although VANET is selforganized and easily deployable, the infrastructure-less vehicular network introduces many challenges that should be tackled before real implementations. For instance, to allow communications between nodes (vehicles) which are out of the power range of each other, some other intermediaries should act as routers, to remedy the lack of dedicated routers. Thus, a distributed routing protocol needs to be employed.

Table - 1 Number of accidents and number of involved: 2001 to 2010 [5]

\begin{tabular}{|c|c|c|c|c|c|}
\hline \multirow{2}{*}{ Year } & \multicolumn{2}{|c|}{$\begin{array}{l}\text { Number of } \\
\text { Accidents }\end{array}$} & \multicolumn{2}{|c|}{$\begin{array}{c}\text { Number of } \\
\text { Persons }\end{array}$} & \multirow{2}{*}{$\begin{array}{c}\text { Acci } \\
\text { dent } \\
\text { Seve } \\
\text { rity } \\
*\end{array}$} \\
\hline & Total & Fatal & Killed & Injured & \\
\hline 2001 & $\begin{array}{c}405,6 \\
37\end{array}$ & $\begin{array}{l}71,219 \\
(17.6)\end{array}$ & 80,888 & 405,216 & 19.9 \\
\hline 2002 & $\begin{array}{c}407,4 \\
97\end{array}$ & $\begin{array}{l}73,650 \\
(18.1)\end{array}$ & 84,674 & 408,711 & 20.8 \\
\hline 2003 & $\begin{array}{c}406,7 \\
26\end{array}$ & $\begin{array}{l}73,589 \\
(18.1)\end{array}$ & 85,998 & 435,122 & 21.1 \\
\hline 2004 & $\begin{array}{c}429,9 \\
10\end{array}$ & $\begin{array}{l}79,357 \\
(18.5)\end{array}$ & 92,618 & 464,521 & 21.5 \\
\hline 2005 & $\begin{array}{c}439,2 \\
55\end{array}$ & $\begin{array}{c}83,491 \\
(19.0)\end{array}$ & 94,968 & 465,282 & 21.6 \\
\hline 2006 & $\begin{array}{c}460,9 \\
20\end{array}$ & $\begin{array}{c}93,917 \\
(20.4)\end{array}$ & $\begin{array}{c}105,74 \\
9\end{array}$ & 496,481 & 22.9 \\
\hline 2007 & $\begin{array}{c}479,2 \\
16\end{array}$ & $\begin{array}{c}101,161 \\
(21.1)\end{array}$ & $\begin{array}{c}114,44 \\
4\end{array}$ & 513,340 & 23.9 \\
\hline 2008 & $\begin{array}{c}484,7 \\
04\end{array}$ & $\begin{array}{c}106,591 \\
(22.0)\end{array}$ & $\begin{array}{c}119,86 \\
0\end{array}$ & 523,193 & 24.7 \\
\hline 2009 & $\begin{array}{c}486,3 \\
84\end{array}$ & $\begin{array}{c}110,993 \\
(22.8)\end{array}$ & $\begin{array}{c}125,66 \\
0\end{array}$ & 515,458 & 25.8 \\
\hline $\begin{array}{c}2010 \\
(\mathrm{P})\end{array}$ & $\begin{array}{c}499,6 \\
28\end{array}$ & $\begin{array}{c}119,558 \\
(23.9)\end{array}$ & $\begin{array}{c}134,51 \\
3\end{array}$ & 527,512 & 26.9 \\
\hline
\end{tabular}

(P): Provisional.

Source: Information supplied by States/UTs (Police Departments).

Figures within parentheses indicate share of fatal accidents to total accidents.

* Accident Severity : No. of Persons Killed per 100 Accidents 


\section{FEATURES OF VEHICULAR AD- HOC NETWORKS (VANETS)}

The unique characteristics of VANETs include

- High mobility with the constraint of road topology: The nodes in VANETs usually are moving at high speed. The node motion is constrained by the road topology and layout. This leads to predictability of node positions, making protection of node privacy harder in VANETs.

- Rapidly changing network topology: In VANETs, vehicle is considered as node. Movement of vehicle is generally changed very frequently and that cause rapid change in network topology.

- Initially low market penetration ratio: This makes it hard for any node to get enough neighbors nearby to support necessary applications.

- Potentially unbounded network size: VANETs could involve the vehicles in one city, several cities, or even a country. Thus, it is necessary to make any protocols for VANETs scalable in order to be practical.

- Anonymous addressee: Most applications in VANETs require identification of the vehicles in a certain region, instead of the specific vehicles. This may help protect node privacy in VANETs.

- Time-sensitive data exchange: Most safety related applications require data packet transmission in a timely manner. Thus, any security schemes cannot harm the network performance of VANETs.

- Potential support from infrastructure: Unlike common MANETs, VANETs can actually take advantage of infrastructure in the future. This property has to be considered to make any protocols and schemes for VANETs better.

- Abundant resources: The VANET nodes have abundant energy, computation resources. This allows for schemes involving usage of resource demanding techniques, such as ECDSA, RSA, etc.

- Better physical protection: The VANET nodes are better protected than those nodes in other MANETs. Thus, VANET nodes are more difficult to compromise, which is also good news for security provisioning in VANETs [6].

\section{MOBILITY MODELS FOR VEHICULAR AD-HOC NETWORKS (VANETS)}

The Mobility Model is having the set of rules that is responsible for generating movement pattern of nodes in adhoc network [1]. With the help of information received from movement pattern, network simulator can generate random topologies depending on node position and also some other task between nodes can be performed. Mobility model can be divided into two types: Macroscopic and Microscopic. Streets, lights, roads, buildings, etc. is considered into the Macroscopic Mobility Model. Microscopic mobility model includes vehicle movements and their behavior. We can also use mobility models as a Traffic generator and Motion generator. The responsibilities of traffic generator are to create random topologies from maps and to define the vehicular behavior under given environment. Motion constraints can be designed by car driver habits, cars and pedestrians and by describing each vehicle movement.

The various parameters like route discovery, route maintenance, route reconstruction, consistency in data and caching mechanism leverages node mobility pattern. Mobility pattern of a node is affected by the following factors [7].

Street Layouts: Streets force nodes to confine their movements to well-defined paths. The spatial distribution of nodes and their connectivity can be found from the constrained movement patterns. Streets can be designed to have more number of lanes e.g. either one or two supporting traffic in either one way or two way direction.

Block size: The smallest area surrounded by streets can be considered as a city block. The block size is useful in determination of number of intersection in the area, which influences the frequency of vehicle obstruction. Also it checks the possibility of communication between two vehicles residing in neighboring intersections. The drawback of larger block size is degradation of performance and make network more sensitive to clustering.

Traffic control mechanisms: The major tools that can be used to control the traffic are stop signs and traffic lights which generally form clusters which in turn lead to the queues of vehicles at intersections. The drawback of this are reduced mobility, slower rates of route change and cluster formation increase wireless channel contention and longer partition which affect network performance.

Interdependent vehicular motion: Every vehicle movement pattern is influenced by its surrounded vehicle movement pattern. For example, while maintaining the minimum distance from the vehicle in front, or while increasing or decreasing the speed, vehicle may change the lane to go into another lane.

Average speed: There are various parameters which may affect the speed of vehicle. For example, as network topology changes, speed of vehicle is changed. Also intersection in route, acceleration or deceleration of vehicles, topology of maps (i.e. map having fewer intersection results into higher speed of vehicle); broken existing routes or establishment of new routes may directly affect the vehicle speed.

Mobility patterns can be generated from different types of models with certain provided criteria. These models are described below [1]:

\subsection{Survey models}

These types of models are used to represent realistic human behaviour specifically in urban mesh environments. Input for these kinds of models are data collected through surveys performed on human activities.

\subsection{Event driven models}

The another name for this kind of model is trace models which has the main functionality of monitoring the movement of human beings as well as vehicles, then analysis of the movement and generation of traces based on movement. The main drawback of these models is co-relation with other traces developed for specific purpose and also the limitation on number of simulators available for such purposes e.g. ELDA (Event Driven Light-weight Distilled State Charts-based Agents) model is an event driven mobility model based on MAO models (Mobile Active Object) and MAS models (Multi Agent Systems) deriving characteristics of behavioral, interaction and mobility models. 


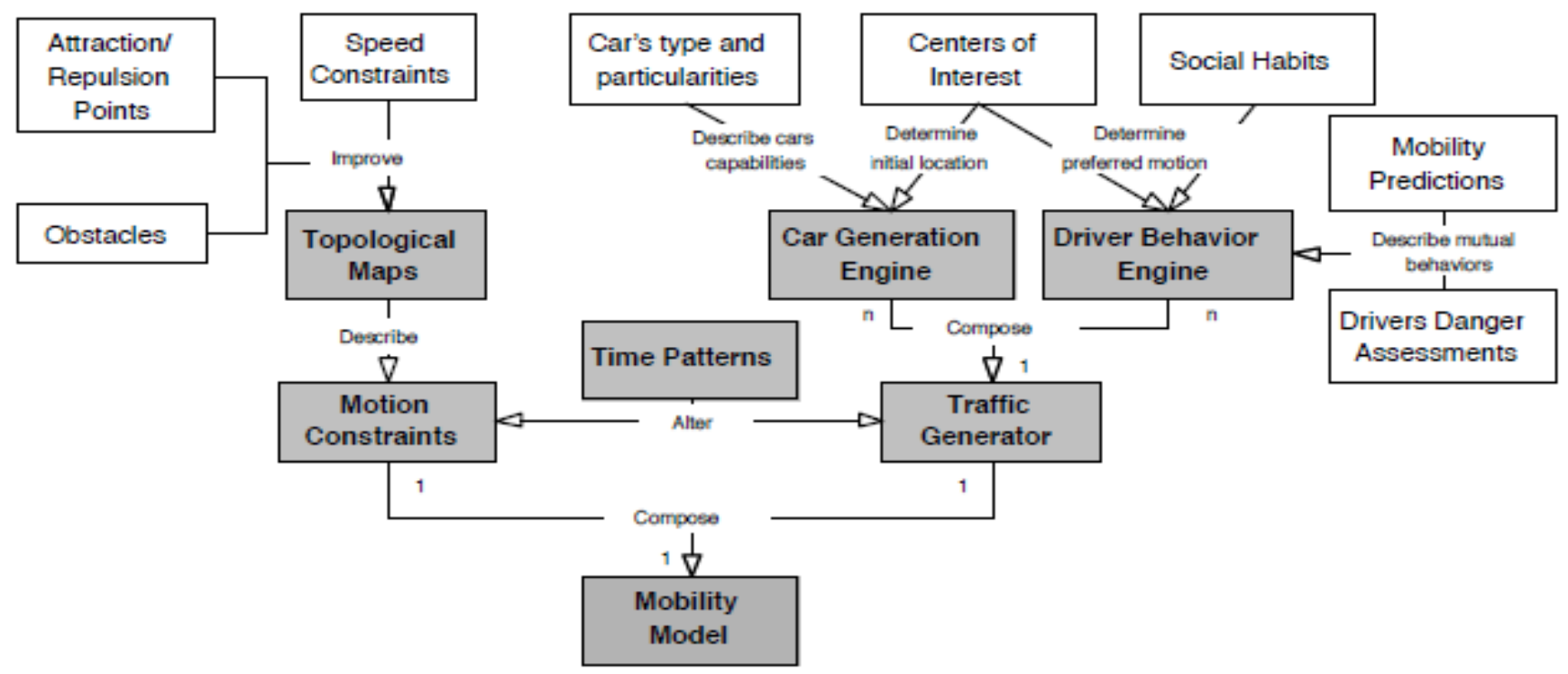

Figure - 1: mobility model generation for inter-vehicle communications [8]

\subsection{Software oriented models}

Simulators that are mainly used for generating traces of urban microscopic traffic are VISIM, CORSIM and TRANSIM. VanetMobiSim uses TIGER database and Voronoi graphs to extract road topologies, maps, streets etc. for the network simulators. The main drawback of such simulators is they can only operate at traffic level and not able to generate realistic levels of details. Moreover insufficient inter-operability with network simulators and insufficient level of generated details for network simulators is major concern.

\subsection{Synthetic models}

Mathematical equations can be used in all models to develop realistic mobility models. In order to make mathematical model strengthen, it is validated against real mobility models. There are various methods of comparison one of them is compare the result obtained by survey and synthetic model.

The division of synthetic model can be done in five categories [8].

- Stochastic model: this type of model mainly deals with totally random motion.

- Traffic Stream model: the main functionality of this model is to examine the mechanical properties of mobility model.

- Car Following model: the main functionality of this model is behaviour monitoring of car-to-car interaction.

- Queue model: this model treats cars as standing in queues and roads as queue buffers.

- Behavioural models: this model examines the influence of social interaction on vehicle movement.

Further Synthetic Model is classified as below:

\subsubsection{Traffic level criteria}

The traffic level presents level of details that are concerned with streets, obstruction in communication paths, lights and vehicular densities. For the simulation to capture details at traffic level, it must include the following traces:

- Movement Topologies
Movement topologies are considered as the key features for simulation. These movement topologies are used to measure some of the important factors like speed and distances, etc. The graph can be considered as a main tool to represent topologies and can be classified into the following three types [9]: Custom graphs: Edges are connected by vertex, (Figure 2(a)). Random graphs: Using algorithms, (Figure 2(b)) which are often Manhattan-grid, Spider, or Voronoi graphs [8]. Topologies from maps: Graphs from GDF (Geographical Data Files) and TIGER database, (Figure 2(c)).

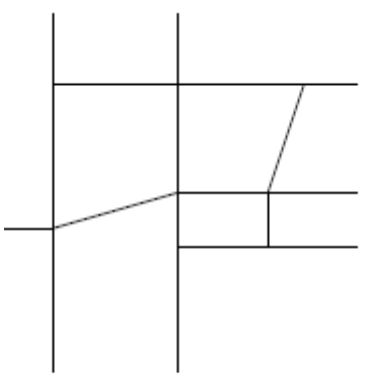

(a)

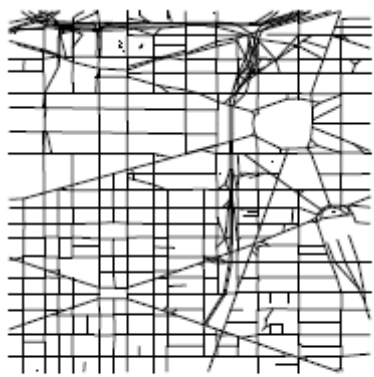

(c)

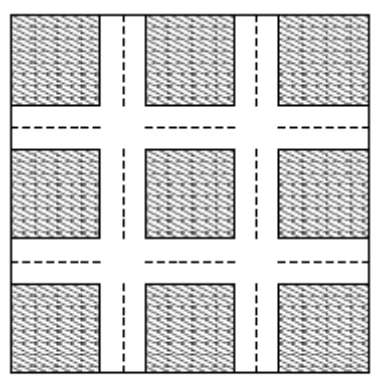

(b)
Figure - 2: Movement Topologies (a) user-defined topology (b) Manhattan-grid map topology (c) TIGER map topology [8]

- $\quad$ Start and end position

The initial position of a node is the time node start its movement and the attracting point can be the path through 
which node traverse and reaches its final position. Initial position and final position can be considered as the start and end point for the vehicle.

- $\quad$ Trip through different positions

During simulation, Vehicle traverses through different points that are called as trip for vehicle.

- Selection of work

The algorithms are used to establish the track between paths.

- Speed of vehicles

The speed of the vehicle can be either smooth or arbitrary depending on the road conditions.

\subsubsection{Motion level criteria}

Main usage of motion level criteria is to create topology between nodes. Also it is helpful for analysing the behaviour of the nodes based on data gathered at traffic level. For example, change of lane while driving. Motion level feature may find the vehicular behaviour from the human behaviour pattern with the help of their movement. In this kind of model, mathematical equations are generally used which are capable of producing all possible vehicular behaviour patterns. Although there are various models available for this category, the most widely used model is the "car following model".

In Car following Model [10], driver behavior can be control by allowing the car to proceed into the same lane. Based on this, we can classify the vehicle as follows: when vehicle is constrained by a preceding vehicle in the same lane, driving at the desired speed, will lead to collision. But when vehicle in not constrained by any other vehicle, it is considered to be free and is allowed to travel with its desired speed. This model has been preferred over other traffic model like Krauss Model (KM), General Motors Model (GM), Gipps Model (GP), and Intelligent Driver Model (IDM) [1].

\subsubsection{Other criteria}

Simulator which is having graphical user interface (GUI) will make the simulator user friendly. Simulation of real world complex scenario has to consider the simulation of radio obstacles in wireless communication medium. Also there should be provision to generate trace files for other simulators such as NS-2 or QualNet.

\section{VEHICULAR AD-HOC NETWORK SIMULATORS}

VANET simulations require two important components: networking component and mobility component. There are separate simulators are available for each component. The functionality of mobility simulator is to build a topology and to produce the trace of vehicle movements. Then after, this trace file is submitted into the network simulator. Recently, researchers are working on development of an integrated simulator which contains both networking and mobility component. Also, there is a provision for exchange of feedback between these two components [11].

Mobility simulators are mainly used to generate the movement pattern between vehicles. Most widely used mobility simulators are TSIS-CORSIM [11], VISSIM [11], PARAMICS [11], SmartAHS [11], Microscopic Traffic Applet [11], CannuMobiSim [11] and VanetMobiSim [12], SUMO [12], FreeSim [12], and CityMob [12].
Likewise, Network simulators are used for communication between mobile nodes. Most widely used network simulators are NS-2 [11, 12], OPNET [11], GloMoSim [12], J-Sim [11], GTNetS [12], and SWANS [11].

In my study, I have given more emphasis towards VANET simulators. Depending on a given application context, the software that allows one to change the behaviour of vehicles is known as an integrated framework or a VANET simulator. In this section, there is a discussion on mainly four VANET simulators, namely GrooveNet [11], TraNS (Traffic and Network simulation Environment) [11], MobiREAL [12], NCTUns (National Chicago Tung University Network Simulator) [12].

\subsection{Groove Net}

It is integrated simulator which provides communication between simulated vehicles and real vehicles. GrooveNet is capable of loading real street map from the TIGER / LINE database. Three different types of simulated node is supported by GrooveNet: (a) vehicles having capability of multihopping data over one or more dedicated short-range communication (DSRC) channels, (b) fixed infrastructure nodes, and (c) mobile gateways capable of Vehicle-to-Vehicle and Vehicle-to-Infrastructure communication. It also supports multiple broadcasting messages informing the current position of vehicle to the neighbors and also vehicle emergency and warning event messages with priority. It supports many operational modes for example, driver mode, simulation mode, playback mode, hybrid simulation mode, and test generation mode.

\subsection{TraNS (Traffic and Network simulation environment)}

TraNS was made by combining NS-2, network simulator and SUMO, mobility simulator in order to provide feedback from the network simulator to the mobility simulator. TraNS has two operating mode: network centric mode and application centric mode. In network centric mode, no feedback is provided from ns-2 to SUMO. Therefore, mobility trace file has to be generated externally and then it is fed into the network simulator. In the application centric mode, TraCI interface is used to provide feedback between ns-2 and SUMO. Application centric mode works if ns-2 and SUMO runs simultaneously.

\subsection{Mobi REAL}

It provides novel approach for the simulation of realistic mobility of nodes and evaluation of MANET applications. Its main feature is that it can simulate mobility of humans and vehicles, and also allow user to change their behavior based on a given application context. This simulator provides facility to describe how mobile node can change their destinations, routes, speeds/directions based on their positions, and information obtained from application. It can simulate MANET network with the help of Georgia Tech Network Simulator (GTNetS). It can also able to produce animation which in turn helps to visualize the node movement, connectivity states and packet transmission. Traffic congestion can be modeled on this simulator. The main feature of this simulator is that it can concurrently 
simulate a mixture of various mobility models. It provides support for vehicular mobility with the help of traffic simulator called NETSTREAM. But its main disadvantage is that users are not able to access and modify the parts of the simulator as it is proprietary software.

\subsection{NCTUns (National Chicago Tung University Network Simulator)}

This simulator was initially developed as network simulator but the latest version NCTUns 4.0 is having capability to integrate some traffic simulation, for example, maps designing and vehicle's mobility controller. NCTUns can also work as an emulator which has a capability of simulation of various protocols used in both wired and wireless networks. It internally uses LINUX TCP/IP protocol stack and able to run any real life UNIX application program on simulated mode without any modification. It also provides efficient GUI that can help user to draw network topologies, configure the protocol module used inside a node, specification about the moving paths of node, plot network performance graphs, and playback the animation of a logged packet transfer trace. The main drawback of this simulator is that it requires Fedora 9 Linux distribution to be installed.

Table - 2 summarize the comparison between VANET simulators.

Table - 2 A comparision of VANET simulators

\begin{tabular}{|c|c|c|c|c|}
\hline $\begin{array}{l}\text { Simulat } \\
\text { or }\end{array}$ & GrooveNet & TraNS & $\begin{array}{l}\text { MobiRE } \\
\text { AL }\end{array}$ & NCTUns \\
\hline $\begin{array}{l}\text { Mobility } \\
\text { Generat } \\
\text { or Used }\end{array}$ & GrooveNet & SUMO & $\begin{array}{l}\text { MobiRE } \\
\text { AL }\end{array}$ & NCTUns \\
\hline $\begin{array}{l}\text { Network } \\
\text { Simulat } \\
\text { or used }\end{array}$ & ----- & $\mathrm{NS}-2$ & $\begin{array}{l}\text { based on } \\
\text { GTNetS }\end{array}$ & ----- \\
\hline $\begin{array}{l}\text { Traffic } \\
\text { Flow } \\
\text { model }\end{array}$ & $\begin{array}{l}\text { Car } \\
\text { following }\end{array}$ & $\begin{array}{l}\text { Car } \\
\text { followin } \\
\text { g SK and } \\
\text { traffic } \\
\text { assignme } \\
\text { nt using } \\
\text { DUA- } \\
\text { Approac } \\
\text { h }\end{array}$ & $\begin{array}{l}\text { Car } \\
\text { followin } \\
\mathrm{g}\end{array}$ & $\begin{array}{l}\text { Car } \\
\text { following }\end{array}$ \\
\hline $\begin{array}{l}\text { Intersect } \\
\text { ion } \\
\text { model }\end{array}$ & $\begin{array}{l}\text { Managed } \\
\text { by traffic } \\
\text { lights }\end{array}$ & $\begin{array}{l}\text { Junction- } \\
\text { based } \\
\text { right-of- } \\
\text { way } \\
\text { rules }\end{array}$ & $\begin{array}{l}\text { Managed } \\
\text { by traffic } \\
\text { lights } \\
\text { and } \\
\text { right-of- } \\
\text { way } \\
\text { rules }\end{array}$ & $\begin{array}{l}\text { Managed } \\
\text { by four } \\
\text { traffic } \\
\text { lights }\end{array}$ \\
\hline $\begin{array}{l}\text { Trip } \\
\text { model }\end{array}$ & $\begin{array}{l}\text { Dijkstra, } \\
\text { sightseeing }\end{array}$ & $\begin{array}{l}\text { Manuall } \\
\mathrm{y} \\
\text { defined, }\end{array}$ & $\begin{array}{l}\text { Manuall } \\
\text { y defined }\end{array}$ & $\begin{array}{l}\text { Manually } \\
\text { defined }\end{array}$ \\
\hline
\end{tabular}

\begin{tabular}{|c|c|c|c|c|}
\hline & & Random & & \\
\hline $\begin{array}{l}\text { Road } \\
\text { topolog } \\
\mathrm{y}\end{array}$ & Any & Any & Any & $\begin{array}{l}\text { User } \\
\text { Defined }\end{array}$ \\
\hline $\begin{array}{l}\text { Traffic } \\
\text { lights }\end{array}$ & $\begin{array}{l}\text { Manually } \\
\text { defined }\end{array}$ & $\begin{array}{l}\text { Manuall } \\
\text { y defined }\end{array}$ & $\begin{array}{l}\text { Manuall } \\
\text { y defined }\end{array}$ & $\begin{array}{l}\text { Automatic } \\
\text { ally } \\
\text { generated } \\
\text { on } \\
\text { intersectio } \\
\text { ns }\end{array}$ \\
\hline $\begin{array}{l}\text { Simulati } \\
\text { on type }\end{array}$ & \multicolumn{4}{|c|}{ Time discrete, microscopic and space-continuous } \\
\hline $\begin{array}{l}\text { Lane } \\
\text { models }\end{array}$ & \multicolumn{4}{|c|}{ Multi-lane streets with lane changing facilities } \\
\hline $\begin{array}{l}\text { Speed } \\
\text { Models }\end{array}$ & $\begin{array}{l}\text { Markov } \\
\text { model, } \\
\text { Uniform, } \\
\text { street- } \\
\text { speed, load } \\
\text { based }\end{array}$ & $\begin{array}{l}\text { Street } \\
\text { speed }\end{array}$ & $\begin{array}{l}\text { Street } \\
\text { speed }\end{array}$ & Random \\
\hline $\begin{array}{l}\text { Mobility } \\
\text { Models }\end{array}$ & $\begin{array}{l}\text { Explicit } \\
\text { origin- } \\
\text { destination, } \\
\text { random } \\
\text { waypoint, } \\
\text { distributed } \\
\text { origin- } \\
\text { destination }\end{array}$ & $\begin{array}{l}\text { Random } \\
\text { and } \\
\text { manually } \\
\text { routes }\end{array}$ & $\begin{array}{l}\text { Probabili } \\
\text { stic } \\
\text { route- } \\
\text { based }\end{array}$ & $\begin{array}{l}\text { Random } \\
\text { and } \\
\text { manually } \\
\text { routes }\end{array}$ \\
\hline $\begin{array}{l}\text { VANET } \\
\text { protocol } \\
\mathrm{s} \text { and } \\
\text { facilities }\end{array}$ & $\begin{array}{l}\text { V-to-V and } \\
\text { V-to-I } \\
\text { communica } \\
\text { tions } \\
\text { multiple } \\
\text { message } \\
\text { types, } \\
\text { which } \\
\text { inform the } \\
\text { current } \\
\text { position of } \\
\text { vehicle to } \\
\text { the } \\
\text { neighbors } \\
\text { and also } \\
\text { vehicle } \\
\text { emergency } \\
\text { and } \\
\text { warning } \\
\text { event } \\
\text { messages } \\
\text { with } \\
\text { priority }\end{array}$ & $\begin{array}{l}\text { Two } \\
\text { ready to } \\
\text { use } \\
\text { VANET } \\
\text { applicati } \\
\text { ons: road } \\
\text { danger } \\
\text { warning } \\
\text { and } \\
\text { dynamic } \\
\text { reroute } \\
\text { (traffic } \\
\text { efficienc } \\
\text { y), } \\
802.11 p \\
\text { support }\end{array}$ & $\begin{array}{l}\text { Initially, } \\
\text { especiall } \\
\text { y } \\
\text { designed } \\
\text { for } \\
\text { MANET } \\
\text { instead } \\
\text { of } \\
\text { VANET }\end{array}$ & $\begin{array}{l}802.11 \mathrm{p} \\
\text { supports } \\
\text { multiple } \\
\text { interfaces } \\
\text { at the } \\
\text { same time } \\
\text { car agents } \\
\text { control } \\
\text { the } \\
\text { driving } \\
\text { behaviour } \\
\text { moving } \\
\text { on the } \\
\text { road }\end{array}$ \\
\hline
\end{tabular}




\begin{tabular}{|l|l|l|l|l|}
\hline $\begin{array}{l}\text { VANET } \\
\text { built-in } \\
\text { applicati } \\
\text { on } \\
\text { support }\end{array}$ & $\begin{array}{l}\text { Vehicle } \\
\text { warning } \\
\text { and } \\
\text { adaptive } \\
\text { rebroadcast }\end{array}$ & $\begin{array}{l}\text { Road } \\
\text { danger } \\
\text { warning } \\
\text { and } \\
\text { dynamic } \\
\text { reroute }\end{array}$ & None & None \\
\hline $\begin{array}{l}\text { GUI } \\
\text { support }\end{array}$ & Yes & Yes & Yes & Yes \\
\hline
\end{tabular}

\section{CONCLUSION}

Currently, there are very few VANET simulators are available which has mobility component and networking component. As per survey, only VANET simulator that can support hybrid simulation is GrooveNet. Most frequently used VANET simulators are NCTUns and GrooveNet. This paper has provided overview of VANET simulators but more improvement and enhancement need to be done in existing simulators so that it can support advance features like feedback between realistic mobility models and realistic networking models.

\section{ACKNOWLEDGMENTS}

I would like to acknowledge my parent who has given moral support and to my wife, for giving inspiration and encouragement in my work.

\section{REFERENCES}

[1] Aamir Hassan, "VANET Simulation", Technical Report, IDE0948, School of Information Science, Computer and Electrical Engineering Halmstad University, May 2009

[2] Marco Fiore1, Jerome Harri2, Fethi Filali2, Christian Bonnet2, "Vehicular Mobility Simulation for VANETs", 1Politecnico di Torino, Corso Duca degli Abruzzi 24 10129 Torino, Italy, 2Institut Euecom, Department of Mobile Communications 06904 Sophia-Antipolis, France

[3] Prof. Vaishali D. Khairnar, Dr. S. N. Pradhan, "Comparative Study of Simulation for Vehicular Ad-hoc Network", International Journal of Computer Applications (0975 - 8887) Volume 4- No.10, August 2010
[4] Djamel Djenouri1, Wassim Soualhi2, Elmalik Nekka2, "VANET's Mobility Models and Overtaking: An Overview", 1 CERIST Center of Research, Ben-aknoun, BP 163, Algiers, 16030, Algeria, 2 National Institute of Computer Science (INI), Oued-Smar, Algiers, Algeria

[5] "Road Accidents in INDIA 2010", GOVVEERRNNMEENTT OF INDIA, MINISTRY OF ROAD TRANSPORT AND HIGHWAYS TRANSPORT RESEARCH WIN, NEW DELHI

[6] Z. Wang, and C. Chigan, "Security of Vehicular Ad Hoc Networks in Intelligent Transportation Systems," in Wireless Technologies for Intelligent Transportation Systems, Nova Science Publishers, 2009 (in press)

[7] Atulya Mahajan, Niranjan Potnis, Kartik Gopalan and AnI A. Wang, "Urban Mobility Models for VANETs", Computer Science, Florida State University

[8] Jerome Harri, Fethi Filali and Christian Bonnet, "Mobility Models for Vehicular Ad Hoc Networks: A Survey and Taxonomy”, Research Report RR-06-168, March, 2006.

[9] Cristian Tuduce and Thomas Gross, "A Mobility Model Based on WLAN Traces and its Validation", in proc. of the IEEE INFOCOM 2005, Miami, March 2005.

[10] Johan Janson Olstam and Andreas Tapani, "Comparison of Car-following models", Swedish National Road and Transport Reaseach Institute, VTI meddelande 960A . 2004

[11] Gongjun Yan, Khaled Ibrahim, and Michele C. Weigle, "Vehicular Network Simulators", in Vehicular Networks, Ed. New York: CRC Press, 2009, pp. $402-423$

[12] Francisco J. Martinez1, Chai Keong Toh2, Juan-Carlos Cano3, Carlos T. Calafate3 and Pietro Manzoni3, "A survey and comparative study of simulators for vehicular ad hoc networks (VANETs)", 1Computer and Systems Engineering Department, University of Zaragoza, Ciudad Escolar, Teruel, Spain, 2Department of EEE, University of Hong Kong, Pokfulam Road, Hong Kong, 3Computer Engineering Department, Technical University of Valencia, Campus de Vera, Spain 